\title{
New Drug Application
}

National Cancer Institute

\section{Source}

National Cancer Institute. New Drug Application. NCI Thesaurus. Code C72899.

A regulatory document submitted to the FDA proposing the approval of a new drug to be marketed and sold in the U.S. It includes supporting data from both animal and human studies that was initially provided in the Investigational New Drug application (IND). 